\title{
Televisão, Violência e Efeitos Midiáticos
}

\author{
Television, violence and media effects
}

Resumo: No mundo contemporâneo, observamos a restrição das relações interpessoais em decorrência da violência nas grandes cidades, do estímulo ao convívio restrito à família e ao par amoroso e da produção da subjetividade individualizada. A ilusão criada pela televisão de que o telespectador participa das situações reproduzidas na tela contribui para com essa restrição, produzindo o espaço público mediatitizado. Dentre as implicações desse processo, trabalhamos com a idéia de o discurso televisivo assumir a função de porta-voz do telespectador, veiculando a violência secundária, ao estabelecer significados para experiências virtuais do sujeito.

Palavras-Chave:Televisão, violência, tempo, espaço.

Abstract:In the contemporary world, we observe the restriction of interpersonal relationships as a consequence of the violence present in the metropolis, of the stimulus to the conviviality restricted to the family and couples and of the production of personalized subjectivity. The illusion created by television that the spectator participates in the situation transmitted by TV contributes to this restriction, producing the mediated public space. Among the implications of this process we discuss the idea that television discourse assumes the function of the spectator's spokesman, expanding secondary violence when it establishes meanings to the virtual experiences of the subject.

Key Words:Television, violence, time, space.

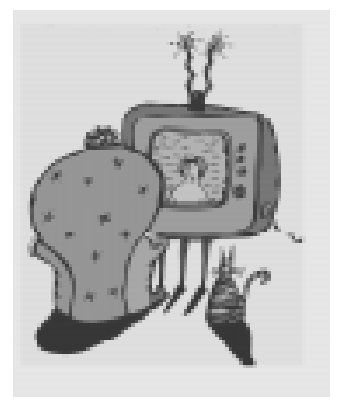

Mériti de Souza

Professora no curso de Psicologia da F.C.L. da Unesp - Universidade Estadual Paulista - Assis; psicóloga. Doutora em Psicologia Clínica pela PUC - S.P..Diretora do Laboratório de Psicopatologia Fundamental da F.C.L. da Unesp. Autora de "A Experiência da Lei e a Lei da Experiência:

Ensaios Sobre Práticas Sociais e Subjetividades no Brasil", Fapesp e Revan, 1999.

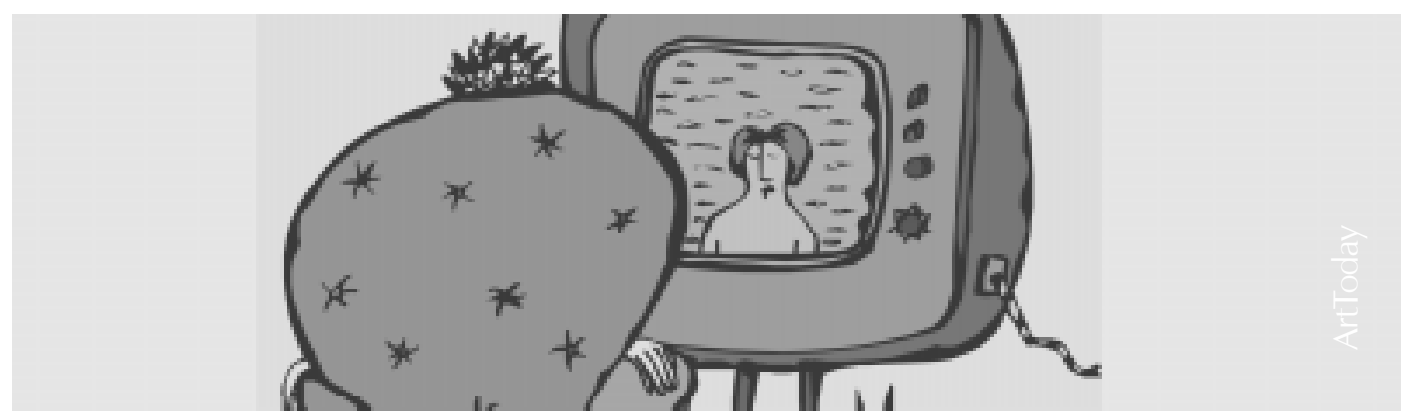

Nas sociedades ocidentais contemporâneas, marcadas pelo consumo, pela massificação e pela violência, observamos, principalmente nos centros urbanos, o crescente abandono dos espaços coletivos, com a rua perdendo seu aspecto de lazer, de espetáculo, e assumindo um caráter utilitarista, de passagem e de transporte. Em contrapartida, a vida íntima e familiar passa a ser cultuada, com atividades como o lazer e a socialização, cada vez mais se restringindo ao ambiente familiar.

No Brasil, é nos grandes centros urbanos que a rede de sociabilidade se articula ao projeto liberal com mais intensidade, explicitando as demandas e os impasses das sociedades modernas. Assim, o brasileiro urbano contemporâneo também encontrase cada vez mais recluso ao espaço de sua casa, restringindo seu convívio à família e a um pequeno grupo. No plano subjetivo, esse contexto estimula o recolhimento afetivo das pessoas, em um processo cada vez maior de ensimesmamento e restrição das suas relações interpessoais (Sennet, 1989).

Chama nossa atenção, nesse processo de valorização da vida familiar e íntima e desvalorização da vida coletiva, o papel desempenhado pela mídia, especialmente pela televisão. Podemos entender a influência da televisão nesse contexto pensando no trabalho relativo à instituição do espaço imaginário e na mediatização da esfera pública, pois, na expressão de Soares (1994), na atualidade encontramos o espaço público mediatizado.

A televisão colabora com a "reorganização do homem com o espaço" através de um processo complexo: ela valoriza o espaço privado ao estimular a vida familiar, ou mesmo solitária, em frente ao aparelho transmissor; ela transmite "notícias e imagens" do que acontece "na rua", simulando a participação do sujeito na vida pública - vide a proposta de televisão interativa. Ao transmitir o que acontece "na rua", ocorre a interpretação do ocorrido, transformando, na maioria das vezes, a versão em realidade; com a seleção do que acontece "na rua", alguns fatos ganham status de realidade e outros se esfumaçam na penumbra do desconhecido.

Nossa discussão remete à idéia de que esse contexto possibilita ao discurso televisivo assumir o lugar de porta-voz do telespectador ao oferecer-lhe a narrativa cultural e social produzida por segmentos da sociedade como sendo seu próprio discurso. 
Postulamos essa idéia com base nas discussões realizadas por Piera Aulagnier (1979), nas quais a autora defende a tese da existência da violência necessária à constituição psíquica do sujeito, denominada violência primária, e daquela considerada desnecessária à vida emocional, e posta a serviço da ordem social, denominada violência secundária.

Com fundamento nesse referencial teórico, supomos que a assunção do discurso televisivo à condição de porta-vOZ do telespectador se torne possível em decorrência de dois procedimentos: primeiro, a associação realizada pelo sujeito entre a violência primária presente no discurso materno e a violência secundária presente no discurso televisivo; segundo, o oferecimento realizado pelo discurso midiático de sentidos e significados de situações que, em sua maioria, não foram, e possivelmente não serão, diretamente vivenciadas pelo sujeito, dificultandoIhe a construção de sentidos e significados singulares.

\section{Discurso Televisivo e Violência Secundária}

Deteremos nossa atenção sobre a tese de Aulagnier (1979) acerca do postulado que rege o Eu e sua relação com o processo secundário, ou seja, para ela, "todo existente tem uma causa inteligível, tornada acessível pelo discurso".

Podemos entender, a partir dessa afirmação, que a linguagem explicita o modo dominante - pelo menos junto ao grupo ao qual pertence o sujeito - que o eu adota como interpretação acerca do mundo ede si mesmo.

Acompanhando o raciocínio da autora, podemos dizer que a utilização, pelo sujeito, de determinados conceitos, expressõese palavras, desvela interpretação queesse mesmo sujeito construiu sobre a realidade, ou seja, explicita o estabelecimento do seu postulado causal, do que eleelegeu como causas, acerca da existência e função dos objetos, situações e sentimentos.

"O primeiro objetivo do processo secundário é adequar o discurso quefala a realidadeà lógica do primário. O processo secundário reconhece o poder autônomo do discurso, não pode negar que ele é portador de significações, mas o conjunto do sistema por elas constituído será interpretado a partir de uma lógica contraditória a esse mesmo sistema. O primário pressupõe o reconhecimento de um exterior, cuja presença e cuja separação não podem ser anuladas; 0 secundário exige o reconhecimento de um discurso portador de significações não arbitrárias, que o informa a respeito do novo postulado lógico o qual ele deverá considerar" (Aulagnier, 1979, p. 99).

Segundo Aulagnier, o decurso do desenvolvimento do sujeito é marcado pela passagem de um psiquismo regido pelo primário para um psiquismo regido pelo secundário. Entretanto, a imagem de coisa e a imagem de palavra apresentam uma junção inicial, ficando as duas atividades sob o primado do mesmo postulado, ou seja, da significação primária, que diz a significação que o bebê atribui à resposta materna às suas demandas. Essas demandas referem-se ao desejo, em termos da mãe dando ou se recusando a dar prazer.

A autora pontua como incontestável a afirmação lacaniana que o sujeito que fala é antes de tudo um sujeito falado; entretanto, aponta essa afirmação como parcial, pois existe uma dificuldade engendrada pelo projeto do Eu, associada ao seu contato com a realidade, que reside

"...na dificuldade do sujeito (inclusive dos teóricos) emaceitar que o que está no poder de seu conhecimento e portanto, no poder do discurso, não se acompanha ipso facto de um poder de modificação, quea ilusão do eu desejaria transformar em um poder de pura esimples anulação" (Id., ibid., p. 103).

Em outras palavras, temos a dimensão identificada (falada) e identidade do eu (o enunciante), sendo que as modificações - psíquicas ou do mundo-ocorrem vinculadas ao trabalho do Eu. Segundo a autora, modificar não significa destruir ou construir a partir do nada: ela se refere ao trabalho do secundário que seempenha em reduzir a representação do mundo produzido pelo primário e os efeitos dessas representações junto ao psiquismo.

Gostaríamos de reter da discussão acima o conceito de postulado causal vinculado ao Eu, suas relações com a linguagem e sua possibilidade de expressar as elaborações do sujeito acerca da realidade que o cerca. Trabalharemos como conceito de porta-voz, pensando no Eu enunciado, ou seja, aquelequeantecedeo Eu enunciante. Aulagnier chama de porta-voz a função de portador de significação e de prótese assumida pelo discurso da mãe junto ao infans, na estruturação de sua psique. Esse processo implica a ação do discurso da mãe, seja representando uma ordem exteriorque apresenta à criança as leis e exigências dessa ordem, seja possibilitando a inclusão do infans na ordem mesma do discurso, pois, desde seu nascimento, a voz materna acompanhou, comentou e acalentou suas manifestações, oferecendo-lhe essa inclusão.

Por seu turno, o conceito de violência assume acepções específicas, na obra da autora, existindo aquela necessária à organização subjetiva e aquela que envolve um "a-mais" nocivo a essa organização. Em outras palavras, ela afirma que a mãee/ou núcleo familiar engendra sobre a criança um tipo de violência denominada primária, que é necessária à constituição psíquica do sujeito. Entretanto, dependendo do ambiente familiar ao qual a criança pertence, um segundo tipo de violência, denominada violência secundária, entendida como desnecessária enociva, pode ser produzida. Dessa forma,

“...propomos separar uma violência primária, que designa o que, no campo psíquico, se impõe do exterior, ao preço de uma primeira violação de umespaço e de uma atividade que obedeceleis heterogêneas ao Eu eao discurso, e umaviolência secundánia, queabreseu caminhoapoiando-sesobreaviolência primária, da qual ela representa um excesso, excesso quase sempre nocivo e desnecessário ao funcionamento do Eu, apesar de sua freqüência" (Id., ibid., p. 36).

Entretanto,

"No segundo caso, contrariamenteao primeiro, a violência se exerceentreo $\mathrm{Eu}$, querse trate de um conflito entre Eus ou de 
um conflito entre um Eu e o diktat de um discurso social, que não tem outra finalidade senão a de se opor a qualquer mudança nos seus modelos. É neste campo conflitual que sesituará o problema do poder, da justificação complementar que ele sempre solicita ao saber e o que disso decorre no plano da identificação... é importante sublinhar que, se esta violência secundária é tão extensa quanto convincente, a ponto de ser ignorada por aqueles que dela são vítimas, é porque ela se apropria abusivamente dos qualificativos necessário e natural, os mesmos que, posteriormente, o sujeito reconhece como próprios da violência primária, do qual se originou o Eu" (Id., ibid., 36/37).

Os qualificativos necessário e natural presentes na violência primária, aos quais a autora se refere, são aqueles transmitidos pela voz materna. Posteriormente, a criança descobre, para além do desejo materno de dar ou recusar prazer, a sujeição dessa voz à questão cultural, expressa pelo sistema de parentesco, pela estrutura lingüística e pelos efeitos dos afetos sobre o discurso.

Assim, da mesma forma como o discurso materno foi tido como "natural e necessário" pela criança, o discurso cultural afeito prioritariamenteà manutenção do status quo também poderá ser encarado como "natural e necessário" pelo adulto. Podemos entender o desconhecimento ou a naturalidade com que o adulto vivencia a violência secundária, produzida por esse tipo de discurso cultural e exercida sobre o $\mathrm{Eu}$, na medida em que esse processo estaria associado à violência primária. Em outras palavras, a transposição das "justificativas" elaboradas acerca da violência primária presente no discurso materno para a violência secundária presente no discurso cultural vinculado ao status quo poderia explicar a "naturalidade" com que o sujeito vivencia os efeitos excessivos dessa violência.

alem do

semântica, do "a-

mais" contido na

antecipação dos

sentidos oferecida ao

sujeito pelo discurso

televisivo, temos o fato

de que a maioria

dos acontecimentos

descritos,

apresentados $\theta$

"traduzidos" pela

televisão

representam

situações não

diretamente

vivenciadas pelo

sujeito.
Amparados por essas discussões, supomos que a manifestação da violência secundária pode ocorrer no campo social. Acreditamos, ainda, que ela encontra sua eficácia e sua condição mais alienante na construção de justificativas e raciocínios que impossibilitam, àqueles que sofrem seus efeitos e mesmo àqueles que a exercem, reconhecer o abuso de poder e de violência aos quais se encontra submetido o seu psiquismo.

Estabelecendo um paralelo com as discussões de Aulagnier, acreditamos encontrar nos agrupamentos sociais a prática ea disseminação da violência secundária realizada através de alguns instrumentos. A mídia, particularmente a televisão, na sua função explícita, surge como rede informativa e de lazer.

Entretanto, ela também dissemina a violência secundária ao assumir para o telespectador a função de porta-voz, veiculando discursos repletos de significados que sustentam a rede social e construindo malha discursiva marcada por uma ordem simbólica hegemônica. Em outras palavras, a mãe funcionou como porta-voz do bebê, oferecendo-lhe, através do seu discurso, sentidos e significados às suas experiências. Posteriormente, o discurso midiático oferece ao telespectador a antecipação de sentidos e de significados acerca do mundo e de situações.

Segundo Aulagnier, a ação da violência alcança sua meta, quando o desejo de quem a exerce converte-se no objeto demandado por parte de quem sofre seus efeitos, ou seja, a violência torna-se invisível, irreconhecível, porque aquele que sofre seus efeitos passa a demandar uma necessidade que se tornou sua a partir do desejo de outro.

No caso do discurso materno, isso acontece porque a mãe oferece à criança um significado com o seio. Existe uma necessidade infantil, porém o desejo da mãe instrumenta essa necessidade ao oferecer-lhe a comida que vem acompanhada do significado antecipado, estabelecendo a demanda específica a partir do desejo da mãe.

Dessa forma, entendemos o discurso midiático, particularmente o veiculado pela televisão, como portador da violência secundária, pois a antecipação de significação que cria uma demanda especifica é oferecida, à exaustão, a um público ávido por informações, notícias e, mais ainda, ávido por interpretações do mundo. Assim, acreditamos que a notícia, acompanhada da interpretação sobre o mundo, oferece esse excesso de significado, esse "a-mais", instrumentalizando a necessidade, na medida em que a informação se transformou em necessidade para o sujeito contemporâneo.

Vale salientar que não se trata, como podemos perceber, de imputar ao discurso televisivo um "desejo", nos mesmos moldes do proposto por Aulagnier acerca do desejo materno. Trata-se, antes, de reconhecer que o discurso materno se encontra carregado de significados oferecidos à criança, antecipando a construção de sentidos das experiências infantis, e que esse processo se assemelha ao processo desencadeado pelo discurso midiático, quando do oferecimento de significados ao público televisivo, dificultando-lhe a possibilidade da construção de sentidos singulares.

Ressaltamos que, além da sobrecarga semântica, do "amais" contido na antecipação dos sentidos oferecida ao sujeito pelo discurso televisivo, temos o fato de que a maioria dos acontecimentos descritos, apresentados e "traduzidos" pela televisão representam situações não diretamente vivenciadas pelo sujeito. Como sabemos, na atualidade a experiência e o contato humano tendem à virtualidade, a constituírem novos campos de sociabilidades e re-ordenamentos na apreensão do real.

\section{Televisão e Experiência Mediatizada}

Nas sociedades contemporâneas, encontramos a demanda informativa e televisiva gerada pela necessidade do sujeito de saber sobre o mundo, estimulada pelo discurso social e pela expansão dos meios de comunicação. No Brasil, encontramos uma holding, a Globopar, que controla uma extensa rede de comunicações no País, possuindo uma emissora de televisão, a Rede Globo, que domina a audiência (Ramos, 1994). Dessa forma, a abrangência de recepção de imagens e idéias veiculadas por uma única rede televisiva possibilita que o discurso televisivo no Brasil exerça sobre o telespectador um efeito de homogeneização, ao disseminar discursos doadores de um sentido único.Esses discursos estimulam a construção, por parte do sujeito, de representações sobre o mundo e sobre ele próprio orientadas por esse viés. 
Até a década de 60, a maioria dos estudos sobre a mídia abordava aspectos ideológicos, ou seja, analisava o conteúdo veiculado pelos meios de comunicação, entendendo-os como neutros e tomando como ponto central de análise a manipulação efetivada por um a um dos veículos a partir do conteúdo veiculado.

Em uma filiação mais próxima aos trabalhos de McLuhan (s/d) - que privilegia o estudo da forma, particularmente da forma assumida pela imprensa contemporânea - as análises atuais são direcionadas ao estudo, por exemplo, da tecnologia, da forma e da dimensão espaço-temporal, sendo esse último aspecto o que nos interessa, visto sua vinculação direta com nossa discussão.

Segundo Senra (1995), a televisão no Brasil foi implantada a partir dos anos cinqüenta, em um momento de tensão com o espaço. Nesse período, tivemos uma grande migração do espaço rural para o urbano, onde esses migrantes se dispersaram, nos grandes centros, a partir da perda do seu local de origem, das orientações e códigos estabelecidos, conhecidos e referenciados a seus laços espaciais anteriores.

Na década de sessenta, a população urbana ultrapassou em número a população rural, com esses migrantes sendo expostos a situações e ambientes totalmente diferenciados dos anteriores. A televisão vai receber essa população, vai apresentar-lhe o mercado e a cidade, oferecendo-lhe códigos que the permitam interpretar suas referências culturais.

Comesse contingente de migrantes, associado à população urbana, ocorre uma adesão à televisão, uma adesão ao tempo em detrimento do espaço, com a televisão instituindo o "espaço imaginário", doravante vivenciado concomitantemente às experiências concretas.

Podemos exemplificar essa discussão com os telejornais que apresentam aos telespectadores imagens referentes a situações que acontecem nos mais distantes pontos do planeta. A maioria da população que assiste aos noticiários dificilmente terá acesso direto a esses lugares e aos acontecimentos descritos, que se reportam aos mais diferentes contextos, como guerras em países distantes, casamentos de princesas ou campeonatos esportivos. Além da dificuldade de grande parcela das pessoas em participar dessas situações, ainda temos os discursos que acompanham essas imagens e as descrevem para o grande público. Entretanto, sabemos que as narrativas que acompanham essas imagens e oferecem sentidos e significados para as situações apresentadas são recortados e definidos a partir de critérios adotados pelas emissoras de televisão, que obedecem a uma série de interesses políticos, sociais e culturais.

Nesse processo também merece menção o papel desempenhado pelas telenovelas, organizadas como verdadeiras fábricas de ensino de novos códigos e comportamentos. A telenovela cumpre essa função ao apresentar aos telespectadores uma gama de situações experienciadas ou não pelo sujeito, que the ofertam significações antecipadas a essas situações. Como vemos, não se trata apenas de apresentação de modelos a serem imitados, mas, sim, de oferecimento de significações prévias a algumas situações que possivelmente não foram vivenciadas concretamente pelas pessoas.
A telenovela realiza exemplarmente a operação de explicitação dos códigos de valores e de comportamentos associados ao íntimo e ao familiar, aliando-os à dimensão temporal. A telenovela transforma o pessoal e familiar em público, expondo relações familiares e afetivas, em uma verdadeira operação de publicização do privado. Ainda, ela "treina" a população, criando um público - aqui no sentido de telespectador - adaptado a essa transformação, ou seja, apto a encarar naturalmente o deslocamento de aspectos e conteúdos do domínio pessoal e íntimo para o domínio coletivo.

Exemplo gritante ocorrido anos atrás foi a notícia estampada na primeira página do jornal carioca "O Globo" acerca da morte de Odete Roithman - personagem de uma novela de grande audiência - em detrimento da notícia do assassinato de Chico Mendes - importante líder ambientalista e sindical - morto no mesmo dia.

Como vemos, o processo de privatização das questões coletivaséestimulado pela televisão (Kehl, 1996), dificultando o contato das pessoas comexperiências que lhes possibilitam acesso a situações diversas das vivenciadas no seu cotidiano. Além disso, as experiências relacionadas ao espaço coletivo encontram-se cada vez mais restritas, tambémemdecorrência da ilusão, criada pelos meios de comunicação, de que o sujeito participa do mundo público e das mais variadas situações reproduzidas no seu instrumento midiático.

Acreditamos que o contato direto do sujeito com novas pessoas e novas experiências possibilita-lhe confrontar suas representações sobre o mundo e questionar os significados por ele construídos sobre a realidade que o cerca e sobre si mesmo. À medida que grande parcela de situações novas acontece no espaço coletivo e nas relações interpessoais, a mediatização do espaço público e o estímulo às experiências virtuais produzidas pela televisão restringem a capacidade do sujeito em atribuir novos sentidos às suas vivências. Essa situação acontece porque, além de a televisão instaurar a experiência virtual, oferecendo ao telespectador o acesso indireto a situações e eventos, ela também oferta uma interpretação única dessas situações, estimulando o telespectador a assumir como seu o discurso proferido.

Como vemos, a partir de aspectos inerentes ao humano como a necessidade de contato com o outro e com o mundo, a sociedade contemporânea produz novas necessidades, sendo uma delas a demanda do homem contemporâneo pela informação oferecida pelos meios de comunicação. Em outras palavras, o estabelecimento de vínculos é condição para a sobrevivência psíquica, porque, dentre outras facetas, oferece ao homem acesso e informações sobre seu entorno e sobre si próprio. $\mathrm{O}$ mundo moderno agrega a essa necessidade pela informação recursos específicos como a tecnologia e os instrumentos midiáticos, possibilitando que a demanda original funcione como substrato à produção da demanda pela informação mediática. Assim, a televisão oferece ao telespectador a ilusão de que ele se vincula a inúmeras pessoas através do seu acesso a informações sobre as mais variadas situações. Esse processo acontece, pois o discurso televisivo assume para o sujeito o papel de portador de significados ao veicular imagens e discursos construídos acerca dessas imagens, ou seja, a interpretação oferecida acerca de uma situação vem corroborada pela verdade das imagens, dificultando a possibilidade de construção de outros enunciados sobre elas.

\section{A telenovela realiza exemplarmente a operação de explicitação dos códigos de valorese de comportamentos associados ao íntimo e ao familiar, aliando-os à dimensão temporal.}


Nessa perspectiva, o telespectador contemporâneo encontra-se cada vez mais excluído da possibilidade de vivenciar e de conhecer novas situações e sentimentos, na medida em que grande parcela dessas situações pode acontecer no espaço público e nas experiências diretas com o outro. Restringe-se, dessa forma, sua capacidade de atribuição de novas significações e sentidos a novas vivências, dificultando mudanças subjetivas e fortalecendo a manutenção de antigas interpretações da sua história pessoal, da sua psique e do mundo.

\section{Tempo, Espaço e Experiência Mediatizada}

"...Construir a realidade tendo como origeme suporte a experiência vivenciada em presença pelos individuos e suas circunstâncias já aparece como obsoleto e não satisfatório."
No mundo contemporâneo, a elaboração da realidade pelo sujeito se ancora nas suas experiências diretas com as situações e as pessoas, bem como nas experiências indiretas ou virtuais. Essas últimas são realizadas através de situações vivenciadas a distância, ou seja, não experimentadas in loco, e ganham dimensão alarmante no cotidiano de grande parcela das pessoas. Rubim (1994) fala das situações televisionadas e vividas simultaneamente pelos telespectadores como produtoras de novas modalidades de vivências televividas, que articulam a realidade através da mescla de percepções provenientes da televivência e das experiências originadas dos contatos interpessoais.

"...Construir a realidade tendo como origem e suporte a experiência vivenciada em presença pelos indivíduos e suas circunstâncias já aparece como obsoleto e não satisfatório. Situações não experimentadas in loco, mas tão somente comunicadas a distância (telecomunicadas) tornam-se, em especial quando acontecidas em simultaneidade, vividas, ou melhor, televividas, em novas modalidades de vivência, sem que isso a rigor signifique experiência. A realidade hoje se constrói então através de complexa mesclagem de perceptos provenientes da vivida experiência e da contemporânea televivência, no sentido do conceito" (Rubim, 1994, pp. 36 e 37).

Ao interpretar o mundo, oferecendo ao sujeito informações acompanhadas de um excesso de significações, o discurso televisivo antecipa a interpretação que esse sujeito virá a fazer sobre essas informações, pois oferece-lhe premissas e diretrizes que influenciam na sua elaboração sobre a realidade. O fato de que esse discurso interpreta situações que dificilmente poderão ser experienciadas pelo telespectador contribui para a inculcação dos sentidos disseminados. Ainda, amparado pelo poder conferido à televisão pelo espectador, esse contexto facilita a aceitação dos valores oferecidos pelo discurso midiático, produzindo um efeito de homogeneização nos discursos e nas subjetividades (Sarlo, 1992).

Conforme ressaltamos acima, o fato de a televisão veicular tanto imagens quanto discursos construídos acerca dessas imagens facilita a assimilação pelo sujeito, ou seja, a interpretação oferecida acerca de uma situação vem corroborada pela verdade das imagens, dificultando a possibilidade de construção de outros enunciados sobre elas.
A televisão, ainda, em virtude da sua abrangência e do fato de trabalhar com o som e a imagem associados, vem dar conta da demanda pela informação e pelo contato com o outro, realizando a mediação entre o espaço público e o privado e entre o sujeito e o mundo.

Para Ortiz (1994), o princípio da circulação e de novas formas de socialização marca a sociedade moderna e implica a apreensão do real organizada por uma nova representação do tempo e do espaço. Isso acontece, pois a assunção das tecnologias de comunicação, em especial da televisão, permite que milhões de pessoas distantes entre si espacial e temporalmente compartilhem a mesma experiência, ou seja, o mesmo recorte da realidade construído pela televisão. Temos, assim, a ruptura entre espaço e tempo, ou melhor, entre a experiência tradicional que o homem tinha com o tempo e com o espaço.

Segundo Senra (1995), a adesão à televisão implica a adesão ao tempo em detrimento do espaço, com a televisão instituindo o "espaço imaginário", vivenciado em substituição ao real. A percepção do espaço e do tempo veiculada pela televisão é específica, pois ela privilegia o tempo, deslocando e abandonando o espaço em decorrência, entre outros aspectos, da dimensão da tela, que apresenta uma limitação. Assim, quando nós "assistimos" à televisão não estamos inscritos no espaço da tela, mas no domínio do tempo.

Essa situação delineia-se através da captura do telespectador em uma rede temporal que "abole" o espaço, utilizando-se de um novo arranjo espaçotemporal criado pelo mundo televisivo que mediatiza o contato do sujeito com seus pares e com o mundo. No extremo dessa situação, temos a abolição do corpo, tornado cada vez mais dispensável nas relações midiáticas.

Neste ponto, vale a pena problematizar a idéia, defendida por alguns teóricos, de quea experiência virtual não implica aspectos a serem criticados, sendo necessário apenas compreender a modalidade de construção do real nela presente. Acreditamos que os conceitos de realidade psíquica e de simbólico servem para trabalharmos a idéia de que o concreto da experiência não garante a qualidade dos vínculos e das relações estabelecidas pelos participantes.

Nessa perspectiva, a relação entre subjetividade e experiência virtual não é linear, nem se expressa por um único referencial no plano do psiquismo. Salientamos, porém, que nosso propósito é o de problematizar a relação entre a constituição subjetiva e a percepção do real, gerada pela especificidade da experiência virtual televisiva. Interessa-nos pensar, nesse processo, a ordem do simbólico elaborada pelo sujeito que instaura ou mantém a falta, associada ou não às experiências virtuais.

Nesse aspecto, a discussão realizada por Gomes (2001) pode auxiliar-nos. A autora utiliza-se dos referenciais analíticos das teorias da Comunicação e da Psicanálise para defender a idéia de que a nova conformação da espacialidade e da temporalidade, associada aos meios de comunicação, produz um tempo ucrônico e um espaço utópico que se revelam como sintomas do contemporâneo. Em outras palavras, a mídia situa os seus receptores no paradoxo do nenhum-tempo-emlugar-algum, ou seja, no vazio têmporo-espacial. A partir dessa idéia, ela acredita que esse rearranjo estimule a obliteração do recalque e da falta, pois a configuração 
da experiência oferecida pelos meios de comunicação apóia-se no fato de as pessoas vivenciarem, através do excesso de velocidade e do desvanecimento do espaço oferecido pelos instrumentos midiáticos, a sensação de liberdade plena e de abandono do lugar subjetivo demarcado pelo tempo-espaço. Assim, esse processo produz a ilusão do controle sobre a falta, ou melhor, a ilusão da saída do lugar subjetivo marcado pela falta.

A autora trabalha ainda outros aspectos, porém interessanos, em sua discussão, o que ela pode auxiliar em nossa idéia de que as novas modalidades assumidas pela configuração espaço-temporal incidem na apreensão do real elaborada pelo sujeito e no que elaboramos como crítica sobre esse processo.

Procurando centrar a discussão, reiteramos nossa idéia de que a mídia, particularmente o discurso televisivo, em decorrência das especificidades da sua atuação na sociedade brasileira e da sua capacidade de instaurar "uma nova dimensão pública de sociabilidade" (Rubim, 1994), possibilita a disseminação não só de conceitos, mas também de formas de pensar e sentir. Assim, o discurso televisivo oferece significados às situações geralmente não vivenciadas pelos telespectadores, o que propaga valores e produz demandas subjetivas, favorecendo a aceitação das interpretações midiáticas como verdadeiras.

Além disso, é oferecido um "a-mais" nessa apresentação de significados (geralmente ofertado pela imagem, que serve de suporte à veracidade da interpretação), possibilitando que o sujeito encare como única e verdadeira essas interpretações acerca do mundo. A esse discurso veiculado pela televisão denominamos, apoiados em Piera Aulagnier (1979), porta-voz e ao trabalho desencadeado por esse discurso associamos a produção da violência secundária.

A violência secundária exercida sobre a subjetividade, a partir do discurso midiático, inviabiliza àqueles que sofrem seus efeitos, e mesmo àqueles que a exercem, perceberem a submissão do seu psiquismo ao esquema de poder e de controle inerente a esse processo. Especificamente, acreditamos que a violência secundária se manifeste através do trabalho do discurso televisivo, ao transportar o telespectador do mundo espaço-temporal para o mundo temporal das experiências mediatizadas, incutindo-lhe a ilusão de uma vida plena de experiências e contatos com o outro, porém privando-o da possibilidade de vivenciar situações e contatos diretos, bem como de atribuir novos sentidos e significados a suas vivências.

Como vemos, a utilização dos discursos televisivos e mesmo de outros instrumentos midiáticos para orientações, transmissão de informações e mesmo atendimentos psicoterapêuticos, como realizados na internet, merece ser considerada nos seus aspectos éticos e técnicos. Entretanto, concomitante a esses aspectos, deve-se observar a relevância da dimensão da temporalidade, da espacialidade e da violência, no universo midiático.
AULAGNIER, P. A Violência da Interpretação. Rio de Janeiro: Imago, 1979 .

FREITAS, J. M. M. Comunicação e Psicanálise. São Paulo: Escuta, 1992.

GOMES, M. R. Repetição e Diferença nas Reflexões Sobre comunicação. São Paulo: Annablume, 2001.

KEHL, M. R. Psicanálise \& Mídia: Você Decide...e Freud Explica. In Chalhub, S. (org.) Psicanálise e o Contemporâneo. São Paulo: Hacker Editores, Cespuc, 1996.

MCLUHAN, M. A Imprensa - Governo por Indiscrição Jornalística. In Os Meios de Comunicação Como Extensões do Homem. São Paulo: Cultrix, (s/d).

ORTIZ, R. Mundialização e Cultura. São Paulo: Brasiliense, 1994.

RAMOS, M. C. Brasil, Mídia, Futuro e Futuro da Política. In: Matos, H. (org.) Mídia, Eleiçõese Democracia. São Paulo: Ed. Página Aberta Ltda, 1994.
RUBIM, A.C. Mídia e Política: Transmissão de Poder. In Matos, H. (org.) Mídia, Eleiçõese Democracia. São Paulo: Ed. Página Aberta Ltda., 1994.

Referências

SARLO, B. Estética y Política: la Escena Massmediática. In Schmuder, H. (org.) Política y Comunicación. Argentina, Universidade de Córdoba, 1992.

SENNETT, R. O Declínio do Homem Público - as Tiranias da Intimidade. São Paulo: Companhia das Letras, 1989.

SOARES, M. C. Televisão e Democracia. In Matos, H. (org.) Mídia, Eleições e Democracia. São Paulo: Página Aberta Ltda., 1994.

SENRA, S. Curso O Espaço Mediático do Programa de Pós-Graduação em Comunicação e Semiótica da PUC- S.P., 1995.

VIRILIO, PA Imagem Virtual Mental e Instrumental. In: Parente, A. (org.) Imagem Máquina: a Era das Tecnologias do Virtual. Rio de Janeiro: Editora 34, 1993. 